OPEN ACCESS

Edited by:

Yusong Li,

University of Nebraska-Lincoln,

United States

Reviewed by:

Kazi Albab Hussain,

University of Nebraska-Lincoln,

United States

Tanushree Parsai,

Indian Institute of Technology

Delhi, India

${ }^{*}$ Correspondence:

Ivan R. Quevedo

ivan.quevedo@ibero.mx

Specialty section:

This article was submitted to

Water and Critical Zone,

a section of the journal

Frontiers in Water

Received: 30 September 2020

Accepted: 17 December 2020

Published: 27 January 2021

Citation:

Tadeo-Jalife NR, Vasquez-Medrano $R$ and Quevedo IR (2021) Assessing the Adsorption of Bipyridinium Herbicides on Model Soil Granular Media.

Front. Water 2:612742.

doi: 10.3389/frwa.2020.612742

\section{Assessing the Adsorption of Bipyridinium Herbicides on Model Soil Granular Media}

\author{
Nahim R. Tadeo-Jalife, Ruben Vasquez-Medrano and Ivan R. Quevedo* \\ Department of Chemical, Industrial and Food Engineering, Universidad Iberoamericana Ciudad de México (UIA), Mexico City, \\ Mexico
}

In this research work, the adsorption of two bipyridinium herbicides (i. e., Diquat and Paraquat) on natural soil and on model soil surfaces has been studied at different water chemistries commonly found in the environment (e.g., pH, supporting electrolyte, and presence of humic or fulvic acids). The experimental work was carried out in the laboratory, using experimental batches of clean quartz sand, silanized quartz sand and sandy soil as a model of agricultural topsoil where herbicides are commonly used and can be adsorbed. The concentrations reached at the equilibrium were analyzed by UVVisible Spectroscopy for the supernatant fraction of the samples. The concentrations were fitted using adsorption isotherms to determine the adsorption mechanisms (i.e., chemisorption or physisorption) at the interface. In general terms, we have encountered that the nature of the soil matrix plays an important role on the study of pollutant adsorption. In experiments carried out on silica sand, the most abundant component of the natural soil matrix, no significant sorption was observed $(<1.5 \mathrm{mg} / \mathrm{g})$ for any of the herbicides. Yet, in experiments carried out on the presence of clay and natural organic matter (i.e., fulvic and humic acids), the adsorption of both herbicides is much higher, likely due to the chemical structure of the molecules that might facilitate the complexation with both herbicides. This investigation improves our understanding of the role that soil granular components play on the absorption of two commonly used herbicides and adequately predict their fate in natural aquatic environments.

Keywords: granular media, sandy soil, sorption isotherms, adsorption kinetcs, paraquat, diquat

\section{INTRODUCTION}

The global demand for food crops is expected to increase between 59 to $98 \%$ by 2050 and farmers have responded by increasing the productivity through the extensive use of agrochemicals (e.g., fertilizers, pesticides, and herbicides) (Valin et al., 2014). Yet, the lack of regulatory measures has caused high pollution levels in the environment and agriculture is now one the main causes of surface and groundwater quality impairments (Rasheed et al., 2018). Agrochemicals deposit on the topsoil and are carried to surface water bodies by overland flow and/or subsurface waterflow contaminating groundwater aquifers (Azizullah et al., 2011; Evans et al., 2018).

In the specific case of herbicides, two of the most commonly used in developing countries due to their non-selective characteristics and low-cost are: Diquat (DQ) and Paraquat (PQ) (Akhavein and Linscott, 1968; Pateiro-Moure et al., 2010). Yet, both compounds are included in the priority 
list of herbicides of potential concern in the European Union and the World Health Organization (WHO) as they pose a risk to the ecosystems and human health (Sechi et al., 1992; World Health Organization. Promotion of Chemical Safety, 1992; Barcelo, 1993; Fortenberry et al., 2016).

Remarkably, despite DQ and PQ belong to the same bipyridine family, share common chemical structure and exhibit high-water solubility, their behavior is known to differ once released in environmental settings (Yeates et al., 1976). Whereas, PQ is more toxic and it has the peculiarity to strongly adhere onto mineral and organic particles present in natural soil, DQ has a higher partition coefficient normalized to carbon organic content $\left(K_{\mathrm{oc}}\right)$ and remain stable for longer time periods (Pateiro-Moure et al., 2010).

The persistence of bipyridynium herbicides in aquatic environments is likely attributed to their adsorption capacity in natural soils, creating complexes with natural organic matter (Iglesias et al., 2010). Different investigations have been conducted to better understand the attachment mechanisms to soil surfaces (Amondham et al., 2006; Iglesias et al., 2010; PateiroMoure et al., 2010, 2013; Gondar et al., 2012; Brigante et al., 2013). Brigante et al. (2007, 2010) studied the adsorption of PQ on Goethite surfaces and reported its significance when Humic Acids (HA) are present in the medium and how the adsorption mechanism is influenced by solution chemistry (i.e., $\mathrm{pH}$ and divalent cations). Iglesias et al. (2010) have also studied PQ under simulated conditions, concluding that iron oxide surfaces enhance its adsorption due to complex formation with NOM on the surface. Pateiro-Moure et al. (2010) assessed the adsorption and desorption competition between three bipyridinium herbicides, namely DQ, PQ and Difenzoquat, identifying stronger bonds and higher adsorption for PQ (i.e., $70-97 \%)$ as compared to the other two to the same surfaces. In another study, Amondham et al. (2006) reported that the Freundlich isothermal model seems to explain the adsorption of PQ under laboratory-controlled conditions.

Based on these studies it is clear that it is essential to understand the role between solution chemistry and soil matrix on the adsorption of PQ and DQ by studying the different components separately. Moreover, other physicochemical properties of the soil surface that have not been addressed in the literature could also interfere with the adsorption of herbicides (Thomaz et al., 2014). For instance, hydrophobicity on agricultural soils is known to impede the rate and extent of wetting and this phenomenon can be enhanced by soil drying, heating from fires and presence of soil nutrients or organic inputs (Hallett et al., 2011). Thus, the need of additional experimental studies considering those aspects will increase our understanding on the persistence of herbicides in the environment.

The objective of this investigation is aimed to compare the adsorption of $\mathrm{PQ}$ and $\mathrm{DQ}$ on different components of the soil matrix (i.e., hydrophilic and hydrophobic sand, presence of NOM, mineral clays, and natural sandy soils) under controlled solution chemistries (i.e., $\mathrm{pH}$, electrolyte) using batch adsorption experiments. The resulting adsorption capacity has been estimated using known isothermal models (i.e., Freundlich and Langmuir) or kinetic models. In general, our results have encountered high affinity of PQ by clay surfaces and hydrophobic sand surfaces in the presence of NOM. DQ has a lower adsorption capacity than PQ, with an adsorption capacity of $3.5-6.3 \mathrm{~L} / \mathrm{mg}$ at concentrations $>10 \mathrm{ppm}$ in the presence of clays. Based on this information, a strategy for the protection of our surface and groundwater bodies can be analyzed as well as proposing different approaches to remediate contaminated sites with those pollutants.

\section{MATERIALS AND METHODS}

\section{Porous Media Preparation}

To better understand the affinity of the studied herbicides in solution to the different components of the natural soil matrix, three experimental stages were proposed as represented in Figure 1.

Stage 1 represents the homogeneous fraction of soil where herbicides; Diquat (DQ) or Paraquat (PQ) (Pateiro-Moure et al., 2010) may interact on hydrophilic acid-washed bare quartz sand (Catalog \#274739, Sigma Aldrich) and on a model hydrophobic surface (i.e., surface-modified quartz sand with aminosilane). Prior to the experiments, the sand used was sieved (U.S. standard mesh size $50-70$ ) to obtain an average grain diameter of $256 \mu \mathrm{m}$ in all the experiments. First, the quartz sand was acid-washed to remove metal and organic impurities and recover the hydrophilicity using the procedure recommended by Litton and Olson (1996). Then, part of the cleaned quartz sand was subjected to anhydrous silanization with aminosilane following the protocol proposed by Chen et al. (2001) to create a highly hydrophobic surface often encountered in agricultural settings (Hallett et al., 2011). In brief, $2 \mathrm{~mL}$ of 3-aminoethyl-3-aminopropyl dimethoxy methyl (AADM) (Catalog \# 371890, Sigma Aldrich); chosen as the silanization agent were added to a beaker containing $2 \mathrm{~mL}$ of $12 \mathrm{~N} \mathrm{HCl}$ (37\% ACS, Sigma Aldrich) to prevent condensation. Then, 500 gr of dried acid washed quartz sand were incorporated to the beaker where $98 \mathrm{~mL}$ of toluene $(99.95 \%$ ACS, Sigma Aldrich) were boiled in a reflux condenser at $130^{\circ} \mathrm{C}$ to remove water and methanol byproducts and kept for $6 \mathrm{~h}$ while stirring. To remove excess materials, the silanized sand grains were washed several times with toluene, followed by acetone (99.5\% ACS, Sigma Aldrich) and deionized water, respectively. Then, the sand grains were allowed to cure overnight at $110^{\circ} \mathrm{C}$ under vacuum and washed with deionized water for $24 \mathrm{~h}$ prior to the adsorption experiments to create the hydrophobic surface.

Stage 2 was proposed to study the interaction of the herbicides with soil surfaces pre-coated with NOM. In these experiments both two common molecules were used to study the adsorption effects, namely Suwanee River Humic Acids (SRHA) and Suwanee River Fulvic Acids (SRFA). SRHA (Catalog \#2S101H, International Humic Substances Society) and SRFA (Catalog \#2S101F, International Humic Substances Society) were prepared at an equivalent concentration of $10 \mathrm{mg} / \mathrm{L}$, and used to pre-coat the bare and surface modified quartz sand grains used in stage 1 . The selected organic molecules are highly soluble in water due to their low molecular 


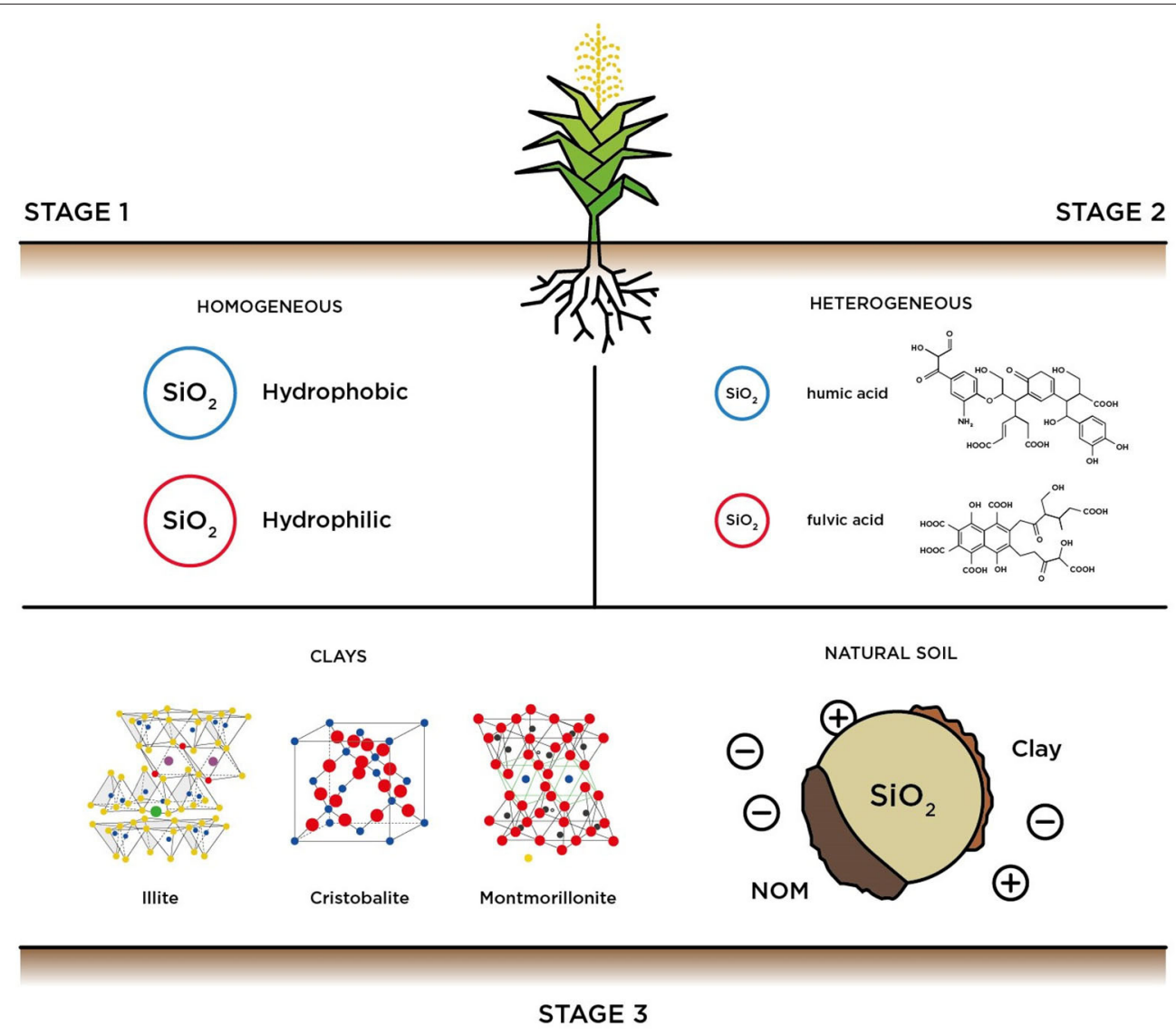

FIGURE 1 | Description of the experimental stages used to assess the adsorption of bypiryridine herbicides.

weight; the SRHA is on the order of $1,490 \mathrm{Da}$, and the SRFA on the order of 1,690 Da, respectively (as reported by the vendor).

Whereas, stage 3 was designed to study the interaction with natural soils: (i) mineral clays extracted from an agricultural topsoil and (ii) sieved topsoil matrix obtained from the same location. As the collected sample was meant to be representative of the natural soil matrix, $\sim 2 \mathrm{~kg}$ of sandy soil was collected from a natural field located at the south of Mexico City (Long. 19.456, Lat. -99.116 ) at a depth of $\sim 2 \mathrm{~m}$. The collected medium was oven dried at $110^{\circ} \mathrm{C}$ for $8 \mathrm{~h}$ to remove moisture. To isolate the clay minerals, the collected sandy soil was sieved trough a $35-50$ mesh $(0.074 \mathrm{~mm})$ to obtain small soil fractions (i.e., clays minerals). According to the authors Díaz-Rodríguez et al. (2011) the composition of the superficial clay minerals isolated in this stage correspond to: Illite $\left[\left(\mathrm{K}, \mathrm{H}_{3} \mathrm{O}\right)(\mathrm{Al}, \mathrm{Mg}, \mathrm{Fe})_{2}(\mathrm{Si}, \mathrm{Al})_{4} \mathrm{O}_{10}\right]$, montmorillonite $\left[(\mathrm{Na}, \mathrm{Ca})_{0.33}(\mathrm{Al}, \mathrm{Mg})_{2}\left(\mathrm{Si}_{4} \mathrm{O}_{10}\right)\right]$ and cristobalite $\left[\mathrm{SiO}_{2}\right]$, whereas clay mineral increase their concentration from 1 to $14 \%$ and $85 \%$ of silica sand. For experiments conducted with the sieved soil, the sample was passed through a 50-70 mesh $(0.297-0.210 \mathrm{~mm})$, to obtain a granulometry comparable to stages 1 and 2. Prior to the experiments the collected medium was also oven dried at $110^{\circ} \mathrm{C}$ for $8 \mathrm{~h}$ to remove moisture.

\section{Preparation of Herbicide Suspensions}

Herbicide suspensions were prepared by adding DQ (Diquat Dibromide Monohydrate Catalog \#45422 Pestanal, Sigma Aldrich) and PQ (Paraquat Dichloride Hydrate Catalog \#34557 Pestanal, Sigma Aldrich) to reach a $0.2 \mathrm{mM}$ concentration in background electrolyte $(16 \mathrm{mM} \mathrm{KCl})$ and adjusting the $\mathrm{pH}$ with $\mathrm{HCl} 10 \% \mathrm{v} / \mathrm{v}$ (37\% ACS, Sigma Aldrich) at two conditions: $6.5 \pm$ 0.5 and $3.5 \pm 0.5$. In all the cases the suspensions were conducted in triplicates and allowed to stabilize for $24 \mathrm{~h}$ before conducting the adsorption experiments.

For the adsorption experiments, $10 \mathrm{~mL}$ of herbicide solutions were added to falcon tubes containing 2 gr of each porous media and allowed to adsorb on the media for at least $24 \mathrm{~h}$ to reach equilibrium. For the experiments with NOM, the bare and surface modified quartz sand a total volume of $4 \mathrm{~mL}$ of SRHA and SRFA stock solution were added and let to equilibrate for at least $24 \mathrm{~h}$ prior to the adsorption experiments with herbicides.

\section{UV-Visible Spectroscopy Measurements}

For the analysis of the initial $\left(\mathrm{C}_{0}\right)$ and equilibrium concentrations (Jegatheesan and Vigneswaran, 2005) of the liquid phase (supernatant) each measurement was assessed using a UV-Visible spectrometer Agilent Model Cary 8454. The UV settings for each herbicide were: DQ and PQ at $310 \mathrm{~nm}$ wavelength and at $258 \mathrm{~nm}$ 
wavelength, respectively. Each measurement was conducted by triplicate and blank experiments were used in all the cases to avoid spectral interferences. It is important to mention that a partial validation of this method was carried out with the results obtained with linearity, accuracy and precision in order to standardize an alternative method for the analysis of this type of samples, making it a robust and more accessible method (Supplementary Information).

In stage 3 the adsorption was too high and fast to reach equilibrium that the adsorption kinetics was measured instead using quartz cells on the UV-Vis. The quartz cells were conditioned by adding $2 \mathrm{~g}$ of the solid phase (mineral clay for stage 3 and natural soil for stage 4 ) and adding $2 \mathrm{~mL}$ of herbicide suspension (DQ or PQ at mean concentrations of the calibration curve) with the same control conditions $\mathrm{pH} 6.5 \pm 0.5$ and $\mathrm{pH} 3.5$ \pm 0.5 in $16 \mathrm{mM} \mathrm{KCl}$ over a time period of $12 \mathrm{~h}$.

\section{Herbicide Adsorption Models}

Sorption of environmental pollutants on soils is often described by either equilibrium or kinetic retention. In this study the equilibrium sorption of herbicides is represented as sorbed concentration vs. the equilibrium concentration in the aqueous phase using sorption isotherms or adsorption kinetics.

\section{Sorption Isotherms}

Sorption isotherms describe the mathematical dependency of sorbed concentration on the equilibrium concentration (Watts, 1998; Al-Ghouti and Da'ana, 2020). The determination of the sorption model parameters from this sorption data is essential for the design of containment facilities, where some of the most used isotherms are the well-known: Langmuir and Freundlich isotherms. Langmuir's model describes the adsorption of adsorbate molecules (herbicide) on the porous media (adsorbent) under the assumption that the adsorbent has a limited capacity. Adsorption sites are assumed identical and retain a molecule of the adsorbate. The mass of adsorbate (mg) per mass of adsorbent $(\mathrm{g})$ at the equilibrium solute concentration $\left(q_{\mathrm{e}}\right)$ (often referred as adsorption at the equilibrium) is the mass of herbicide per mass of porous media (1).

$$
q_{e(\text { Langmuir })}=\frac{Q K_{l} C_{e}}{1+K_{l} C_{e}}
$$

Where, $Q(\mathrm{mg} / \mathrm{g})$ is the maximum amount of adsorbate per unit weight of the adsorbent to form a complete monolayer on the surface, $K_{1}(\mathrm{~L} / \mathrm{mg})$ is the Langmuir constant related to the affinity of the binding sites and $C_{\mathrm{e}}(\mathrm{mg} / \mathrm{L})$ is the concentration of adsorbate in solution at the equilibrium (Nethaji et al., 2013).

Freundlich's exponential model is coupled to a heterogeneous system or interface, which is considered layered (physisorption), since it describes the application of retention in the medium in different layers $\left(\mathrm{q}_{\mathrm{e}}\right)$. Thus, the distribution of each of the associated energies adsorption on active sites is not considered at a single interface (2).

$$
q_{e(\text { Freundlich })}=K_{f} \cdot C_{e}^{1 / n}
$$

where $C_{\mathrm{e}}(\mathrm{mg} / \mathrm{L})$ is the concentration of adsorbate in the solution, $K_{f}$ is the specific constant of the adsorption capacity obtained in the intercept of the linear Freundlich model and $1 / n$ is the measure of the intensity of the adsorption (Al-Ghouti and Da'ana, 2020).

\section{Adsorption Kinetics}

The kinetic models of adsorption determine the dynamics of the adsorption processes in a liquid phase system. The pseudofirst order (PFO) adsorption model is based on the adsorption capacity of the solid where the ions besieged on the adsorbent (3) (Kaur et al., 2016):

$$
\frac{d q_{t}}{d t}=k_{1} \cdot\left(q_{e q}-q_{t}\right)
$$

Mass transfer is considered proportional as the controlling stage of the process as a function of time $\left(\frac{d q_{t}}{d t}\right), q_{\mathrm{t}}(\mathrm{mg} / \mathrm{g})$ is the amount adsorbed onto adsorbent at time $t, q_{\mathrm{eq}}(\mathrm{mg} / \mathrm{g})$ is the amount adsorbed at equilibrium and $k_{1}$ (Al-Ghouti and Da'ana, 2020) is the rate constant of adsorption.

The pseudo-second order (PSO) model assumes that the solute adsorption rate $\left(\frac{d q_{t}}{d t}\right)$ is proportional to the available sites on the adsorbent. And the reaction rate depends on the amount of solute on the surface of the adsorbent-the driving force is proportional to the number of active sites available on the adsorbent (4) (Aydin et al., 2018).

$$
\frac{d q_{t}}{d t}=k_{2} \cdot\left(q_{e q}-q_{t}\right)^{2}
$$

Where $q_{\mathrm{t}}(\mathrm{mg} / \mathrm{g})$ is the amount adsorbed onto adsorbent at time $t, q_{\text {eq }}(\mathrm{mg} / \mathrm{g})$ is the amount adsorbed at equilibrium and $k_{2}$ is the second order rate constant of adsorption.

\section{RESULTS AND DISCUSSION \\ Adsorption of Herbicides on Homogenous Porous Media (Stage 1)}

Figures 2A,B represent the results for batch sorption experiments of DQ and PQ on clean quartz sand (QS) and silanized quartz sand (SS), respectively. As described in the materials and method section, each herbicide was suspended in $\mathrm{KCl}$ electrolyte and allowed for $24 \mathrm{~h}$ to adsorb on the media to reach equilibrium. The adsorption at the equilibrium $\left(q_{\mathrm{e}}\right)$ was plotted vs. the concentration in the aqueous phase $(\mathrm{Ce})$ and the results were adjusted as Langmuir or Freundlich adsorption isotherms models (Table 1). In general, we observed that the $q_{\mathrm{e}}$ for DQ and PQ at the studied conditions in QS and SS was low $\left(q_{\mathrm{e}}<0.6 \mathrm{mg} / \mathrm{g}\right.$ and $q_{\mathrm{e}}<0.7 \mathrm{mg} / \mathrm{g}$, for DQ and PQ, respectively), so it can be concluded that bare QS and SS are not particularly relevant when referring to sorption of the studied herbicides regardless of the solution chemistry. Yet, there are some variances on the adsorption trends between both herbicides to the same bare surface. In experiments conducted with DQ (Figure 2A), the isotherms for DQ on clean quartz sand exhibit an adsorption behavior characterized by a Freundlich model $(1 / n>1)$. In other words, it is likely that the DQ presents physisorption on the surface of sand for both $\mathrm{pH}$ conditions (i.e., 3.5 and 6.5). The fitted $K_{\mathrm{f}}$ parameters shows that for DQ is 0.04 

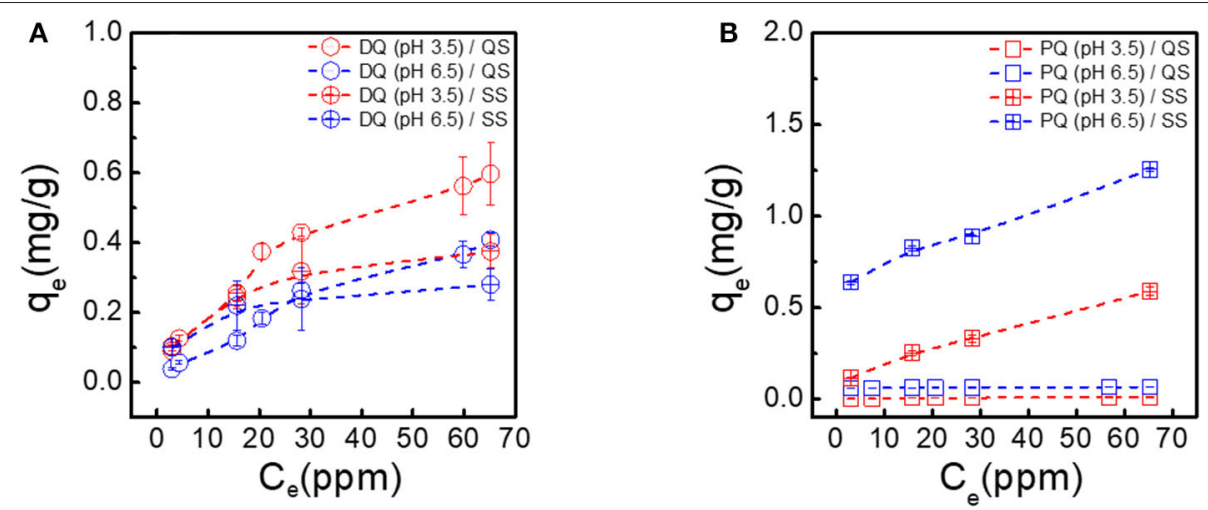

FIGURE 2 | Freundlich adsorption isotherms on clean quartz sand (QS) and silanized sand (SS) for (A) DQ (०) and (B) PQ ( $\square$ ) dissolved in KCl electrolyte adjusted at two pH conditions, pH 3.5 and pH 6.5. Dashed lines are included as eye guide, and error bars represent 95\% confidence intervals.

TABLE 1 | Summary of calculated Langmuir and Freundlich isotherm adsorption parameters for PQ and DQ on quartz sand (QS) and silanized sand (SS).

\begin{tabular}{|c|c|c|c|c|c|c|}
\hline \multirow{2}{*}{$\begin{array}{l}\text { Experimental } \\
\text { conditions }\end{array}$} & \multicolumn{3}{|c|}{ Langmuir isotherm model } & \multicolumn{3}{|c|}{ Freundlich isotherm model } \\
\hline & $\begin{array}{c}K_{I} \\
(\mathrm{~L} / \mathrm{mg})\end{array}$ & $\begin{array}{c}Q \\
(\mathrm{mg} / \mathrm{g})\end{array}$ & $r^{2}$ & $1 / n$ & $\begin{array}{c}K_{f} \\
(\mathrm{~L} / \mathrm{mg})\end{array}$ & $r^{2}$ \\
\hline DQ (pH 3.5)/QS & $0.019 \pm 0.00$ & $0.888 \pm 0.00$ & 0.939 & $0.570 \pm 0.02$ & $0.043 \pm 0.01$ & 0.973 \\
\hline DQ (pH 6.5)/QS & $0.009 \pm 0.00$ & $0.604 \pm 0.00$ & 0.977 & $1.196 \pm 0.01$ & $0.014 \pm 0.00$ & 0.988 \\
\hline$P Q(\mathrm{pH} 3.5) / Q S$ & $0.004 \pm 0.00$ & $1.133 \pm 0.00$ & 0.964 & $0.984 \pm 0.00$ & $0.004 \pm 0.00$ & 0.981 \\
\hline$P Q(p H 6.5) / Q S$ & $0.003 \pm 0.00$ & $0.830 \pm 0.00$ & 0.821 & $0.989 \pm 0.00$ & $0.003 \pm 0.00$ & 0.939 \\
\hline DQ (pH 3.5)/SS & $0.017 \pm 0.00$ & $0.505 \pm 0.00$ & 0.334 & $0.455 \pm 0.03$ & $0.053 \pm 0.03$ & 0.684 \\
\hline DQ (pH 6.5)/SS & $0.023 \pm 0.00$ & $0.319 \pm 0.01$ & 0.684 & $0.359 \pm 0.04$ & $0.059 \pm 0.05$ & 0.961 \\
\hline$P Q(p H 3.5) / S S$ & $0.033 \pm 0.00$ & $0.814 \pm 0.00$ & 0.570 & $0.509 \pm 0.03$ & $0.078 \pm 0.00$ & 0.583 \\
\hline PQ (pH 6.5)/SS & $0.019 \pm 0.00$ & $1.646 \pm 0.03$ & 0.114 & $0.735 \pm 0.05$ & $0.036 \pm 0.00$ & 0.703 \\
\hline
\end{tabular}

Data represent the mean $\pm 95 \%$ confidence interval.

and $0.01 \mathrm{~L} / \mathrm{mg}$, respectively. Yet, in an acid medium ( $\mathrm{pH} 3.5)$, greater adsorption of the DQ is observed. The phenomenon is the most common adsorption mechanism for organic contaminants on soil substrates and are attributed to electrostatic bonds as result of the charged charging forces associated between the sorbent and sorbate (Al-Ghouti and Da'ana, 2020). This seems to agree with the results observed at solutions with an acidic $\mathrm{pH}$ where the expected electrostatic forces at the sand grain will be less negative ( $\mathrm{pzc} \sim 2.4 \mathrm{pH}$ ) (Cloarec et al., 2016). Also, the adsorption on silanized sand (SS) seems to exhibit a comparable behavior as it was on clean sand.

For experiments conducted with PQ (Figure 2B), the adsorption capacity on QS is comparable to DQ, were physical adsorption is likely to be the mechanism. Although, for experiments conducted on SS, PQ seems to adsorb better on the surface reaching the maximum concentration at $\mathrm{pH}$ 6.5. SS is a model of contaminated soils or grasslands burned by fires, causing the surface soil to exhibit a hydrophobic character (Hallett et al., 2011). Interestingly, the adsorption capacity on SS seems to be higher for PQ as compared to DQ. Yet, none of proposed adsorption isotherm models (i.e., Langmuir nor Freundlich) seems an accurate model $\left(r^{2}<0.703\right)$ to predict the mechanism: chemisorption or physisorption.

\section{Adsorption of Herbicides on Heterogenous Porous Media (Stage 2)}

Figures 3A,C represent the adsorption isotherms for DQ on QS and SS media pre-coated with both model NOM molecules, namely SRHA and SRFA. In general terms, higher adsorption of DQ ( $q_{\mathrm{e}}$ up to $2 \mathrm{mg} / \mathrm{g}$ ) in the presence of SRHA and SRFA is observed as compared to the bare QS surface $\left(q_{\mathrm{e}} \sim 0.6 \mathrm{mg} / \mathrm{g}\right)$ under acidic conditions ( $\mathrm{pH}$ 3.5) on QS. Yet low adsorption of DQ $\left(q_{\mathrm{e}}<0.17 \mathrm{mg} / \mathrm{g}\right)$ is observed on SS media regardless of the NOM molecule used and $\mathrm{pH}$. By looking closely at the shape of the curves and the fitted adsorption parameters (Table 2), is clear that in the presence of NOM, the adsorption mechanism for DQ is chemisorption. The Langmuir isotherm represents more closely the observed adsorption mechanism $\left(0.961>r^{2}\right.$ $>0.992$ ). In Langmuir adsorption models, adsorbates form a monolayer on the surface when it becomes saturated and each site can contain only one species chemically attached (Al-Ghouti and Da'ana, 2020). Examination of the $K_{l}$ parameters shows that 

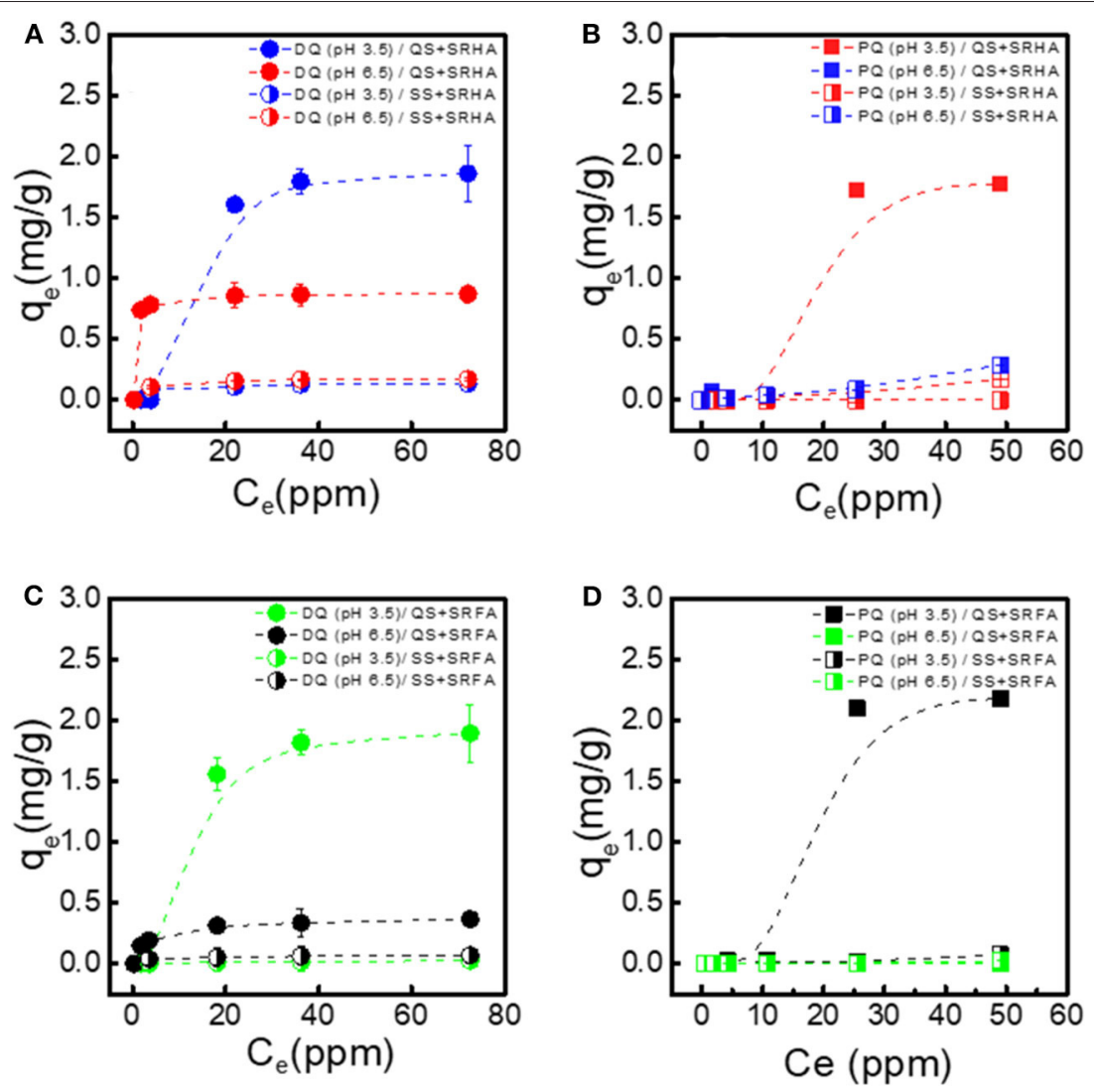

FIGURE 3 | In (A,C) Langmuir adsorption isotherms on clean quartz sand (QS) and silanized sand (SS) for DQ (o) dissolved in KCl electrolyte adjusted at two pH conditions, pH 3.5 and pH 6.5 supplemented with Suwannee River Humic Acid (SRHA). In (B,D) adsorption isotherms on clean quartz sand (QS) and silanized sand (SS) for PQ ( $\square$ ) dissolved in KCl electrolyte adjusted at two pH conditions, pH 3.5 and pH 6.5 with Suwannee River Fulvic Acid (SRFA). Dashed lines are included as eye guide, and error bars represent $95 \%$ confidence intervals.

TABLE 2 | Calculated Langmuir and Freundlich isotherm adsorption parameters for PQ and DQ adsorption on quartz sand (QS) and silanized sand (SS) pre-coated with model NOM molecules: SRHA and SRFA.

\begin{tabular}{|c|c|c|c|c|c|c|}
\hline \multirow{2}{*}{$\begin{array}{l}\text { Experimental } \\
\text { conditions }\end{array}$} & \multicolumn{3}{|c|}{ Langmuir isotherm model } & \multicolumn{3}{|c|}{ Freundlich isotherm model } \\
\hline & $\begin{array}{c}K_{1} \\
(\mathrm{~L} / \mathrm{mg})\end{array}$ & $\begin{array}{c}Q \\
(\mathrm{mg} / \mathrm{g})\end{array}$ & $r^{2}$ & $1 / n$ & $\begin{array}{c}K_{\mathrm{f}} \\
(\mathrm{L} / \mathrm{mg})\end{array}$ & $r^{2}$ \\
\hline $\mathrm{DQ}(\mathrm{pH} 3.5) / \mathrm{QS}+\mathrm{SRHA}$ & $1.149 \pm 0.06$ & $1.902 \pm 0.07$ & 0.969 & $0.920 \pm 0.01$ & $0.099 \pm 0.00$ & 0.723 \\
\hline $\mathrm{DQ}(\mathrm{pH}$ 6.5)/QS+SRHA & $1.341 \pm 0.05$ & $0.882 \pm 0.45$ & 0.961 & $0.606 \pm 0.01$ & $0.127 \pm 0.01$ & 0.513 \\
\hline$P Q(p H$ 3.5)/QS+SRHA & $3.544 \pm 0.00$ & $1.802 \pm 0.62$ & 0.962 & $0.883 \pm 0.07$ & $0.163 \pm 0.00$ & 0.543 \\
\hline $\mathrm{DQ}(\mathrm{pH} 6.5) / \mathrm{QS}+\mathrm{SRFA}$ & $0.119 \pm 0.00$ & $0.412 \pm 0.04$ & 0.897 & $0.506 \pm 0.01$ & $0.126 \pm 0.01$ & 0.425 \\
\hline $\mathrm{PQ}(\mathrm{pH} 3.5) / \mathrm{QS}+\mathrm{SRFA}$ & $6.333 \pm 0.04$ & $2.200 \pm 0.87$ & 0.992 & $0.888 \pm 0.06$ & $0.199 \pm 0.00$ & 0.473 \\
\hline $\mathrm{DQ}(\mathrm{pH} 3.5) / \mathrm{SS}+\mathrm{SRHA}$ & $0.072 \pm 0.00$ & $0.159 \pm 0.01$ & 0.992 & $0.096 \pm 0.01$ & $0.243 \pm 0.02$ & 0.670 \\
\hline DQ (pH 6.5)/SS+SRHA & $0.196 \pm 0.00$ & $0.182 \pm 0.03$ & 0.838 & $0.142 \pm 0.01$ & $0.455 \pm 0.02$ & 0.205 \\
\hline $\mathrm{PQ}(\mathrm{pH} 3.5) / \mathrm{SS}+\mathrm{SRHA}$ & $0.027 \pm 0.00$ & $0.276 \pm 0.01$ & 0.988 & $0.370 \pm 0.06$ & $0.050 \pm 0.01$ & 0.920 \\
\hline $\mathrm{PQ}(\mathrm{pH}$ 6.5)/SS+SRFA & $0.024 \pm 0.00$ & $0.040 \pm 0.00$ & 0.996 & $0.066 \pm 0.01$ & $0.063 \pm 0.00$ & 0.115 \\
\hline
\end{tabular}


TABLE 3 | Calculated PFO and PSO adsorption kinetics for PQ and DQ dissolved in $\mathrm{KCl}$ electrolyte on Mineral Clay and Sandy Soil.

\begin{tabular}{lcclll}
\hline \multirow{2}{*}{$\begin{array}{l}\text { Experimental } \\
\text { conditions }\end{array}$} & \multicolumn{2}{c}{ PFO model } & & \multicolumn{2}{c}{ PSO model } \\
\cline { 2 - 3 } & $\begin{array}{c}\boldsymbol{k}_{\mathbf{1}} \\
\left(\mathbf{m i n}^{-1}\right)\end{array}$ & $\boldsymbol{r}^{\mathbf{2}}$ & & $\begin{array}{c}\boldsymbol{k}_{\mathbf{2}} \\
\left(\mathbf{p p m} \cdot \mathbf{m i n}^{-1}\right)\end{array}$ & $\boldsymbol{r}^{2}$ \\
\hline DQ/Mineral clay & 0.0019 & 0.993 & & 0.00007 & 0.959 \\
PQ/Mineral clay & 0.0013 & 0.787 & & 0.00006 & 0.897 \\
DQ/Sandy soil & 0.0079 & 0.684 & & 0.00300 & 0.534 \\
PQ/Sandy soil & 0.0074 & 0.778 & & 0.00200 & 0.285 \\
\hline
\end{tabular}

for DQ ranged from 0.12 to $1.34 \mathrm{~L} / \mathrm{mg}$ on QS and 0.005 and 0.096 $\mathrm{L} / \mathrm{mg}$ on SS.

Likewise, in experiments conducted with PQ (Figures 3B,D) on both surfaces (QS and SS) precoated with both NOM molecules (SRHA and SRHA), the interaction resembles the Langmuir model chemisorption $\left(0.962>r^{2}>0.996\right)$ observed with DQ (Table 2). The adsorption of PQ on surfaces coated with SRHA and SRFA under neutral conditions ( $\mathrm{pH}$ 6.5) is low and comparable $\left(q_{\mathrm{e}} \sim 0.5 \mathrm{mg} / \mathrm{g}\right)$, whereas in the acid medium $(\mathrm{pH} 3.5) q_{\mathrm{e}}$ is up to $2 \mathrm{mg} / \mathrm{g}$ of PQ is adsorbed on QS. The $K_{l}$ parameters shows that PQ is more strongly attached to the QS surface than the PQ under acidic conditions ( $\mathrm{pH} 3.5$ ) a the values ranged from 3.544 to $6.333 \mathrm{~L} / \mathrm{mg}$.

Proper understanding of the interactions between bipyridinium herbicides and NOM contained on the soil matrix is hindered by the complex structure of NOM and the numerous interactions (e.g., electrostatic attraction, hydrophobic bonding, and cation exchange capacity) might occur simultaneously (Khan and Schnitzer, 1978).

\section{Adsorption on Isolated Clay Minerals and Sandy Soil (Stage 3)}

Sandy soil was used to conduct the experiments on Stage 3. The sandy soil was comprised by $85 \%$ sand and $10 \%$ NOM and 5\% mineral clays, respectively (Díaz-Rodríguez et al., 2011). Mineral clays are important sorbent materials for bipyridinium herbicides and should be investigated individually since it could prevent herbicides from leaching and contaminate surface and groundwaters (Pateiro-Moure et al., 2009). For the specific sandy soil used here the predominant clays were: Montmorillonite, Illite, and Cristobalite. Mineral clays were sieved through a 200 mesh $(0.074 \mu \mathrm{m})$, whereas the sandy soil was sieved through a $70-50$ mesh $(210 \mu \mathrm{m})$ to obtain a comparable granular size to the medium used to Stages $1 \& 2$. The adsorption kinetics was assessed after 1,440 $\min (24 \mathrm{~h})$.

In the adsorption measurements conducted on the extracted mineral clays, it was shown that DQ is adsorbed after $7 \mathrm{~h}$, whereas for the PQ an approximate time of $8 \mathrm{~h}$ was required to reach equilibrium. It is likely that under these circumstances, the larger surface area increases the contact surface, which is why we hypothesize it manages to reach equilibrium more quickly (Rytwo et al., 1996; Nir et al., 2006). It can be inferred that the DQ adsorbs faster than the PQ. In experiments conducted on mineral clays the PFO order seems to highly accurate $\left(r^{2} \sim 0.993\right)$ to predict the adsorption kinetics of DQ, whereas the PSO model is better to represent the adsorption of PQ $\left(r^{2} \sim 0.897\right)$ (Table 3$)$.

One of the most relevant results are those obtained with natural soil (Figure 4). The DQ kinetics showed that at a time of $12 \mathrm{~h}$ the herbicide only adsorbs $80 \%$, different from the experiments with mineral clays, the collected soil is the same only that in this phase it was sieved with a 70-50 mesh. Comparison the PQ was completely adsorbed. This is likely due to the particle size of the soil, as dissimilar to clay minerals that have a greater contact surface and greater porosity (Nir et al., 2006). It is also important to add that between both herbicides, the PQ has a greater affinity to dissociate in the medium and complex with organic matter. While DQ resembles phase 2 experiments where it is not completely adsorbed in the presence of NOM, saturating the granular medium at very high concentrations.

\section{DISCUSSION}

In environmental settings, adsorption models are used to describe the interaction mechanisms between organic pollutants (e.g., herbicides, pesticides, etc.) and the natural soil matrix (e.g., sand, NOM, clay, silt, etc.) where they are released (Khan and Schnitzer, 1978; Nir et al., 2006; Pateiro-Moure et al., 2013). Yet, the complexity of the natural soil matrix (i.e., sorbent), difficult the accurate characterization of the physicochemical interactions of organic pollutants with the soil fractions (i.e., sorbates) (Pateiro-Moure et al., 2013). Thus, a more systematic approach is desired to clearly identify the interaction mechanisms with each pollutant and each component of the soil matrix, individually.

Adsorption isotherms are a helpful way to describe the interaction mechanisms based on the interaction strength between sorbate-sorbent; whereas physisorption occurs due to the weak electrostatic interactions (e.g., London forces, Dipole-dipole forces) chemisorption arises when the adsorbate and the substrate are attached by covalent bonds (Khan and Schnitzer, 1978).

In experiments conducted with acid washed sand and silanized sand, the Freundlich isotherm, indicative of physisorption, seems to represent better the interaction mechanisms for both herbicides, DQ and PQ. The observed Freundlich model is an indicative of the reversible and weak adsorption of the both herbicides on the quartz sand and it is not restricted to a monolayer formation. Different investigations with herbicide adsorption on topsoil samples have demonstrated the application of this model to investigate the adsorption of herbicides from aqueous solutions while suspended on different solution chemistries (Pateiro-Moure et al., 2009, 2010; Kaur et al., 2016). Kaur et al. (2016) reported that the Freundlich isotherm model accurately described the adsorption and desorption behavior of Pretilachlor, a chloroacetanilide herbicide used in India, on three different soils $\left(r^{2}>0.97\right)$ with varying physicochemical characteristics. Likewise, Pateiro-Moure et al. (2009, 2010) used Freundlich isotherms showed that the best fits for PQ and DQ onto vineyard- devoted soils, loam and sandy loam soils.

In experiments conducted with model granular media in the presence of both NOM, Langmuir isotherms describe better the adsorption of the herbicide on the granular surface. 

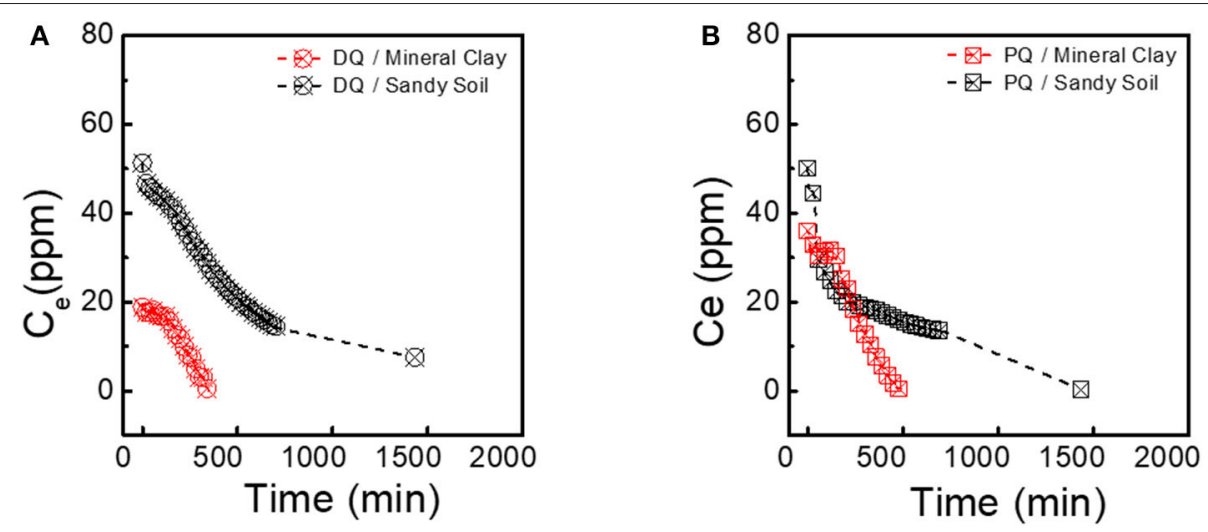

FIGURE 4 | Representative adsorption kinetics of: (A) electrolyte supplemented with DQ, and in (B) electrolyte supplemented with PQ onto mineral clay medium and sandy soil.

The Langmuir isotherm accounts for the surface coverage by balancing the dynamic equilibrium (i.e., rates of adsorption and desorption should be equal). Under this process, adsorption is proportional to the fraction of the surface of the adsorbent that is open while desorption is proportional to the fraction of the adsorbent surface that is covered. Langmuir isotherm is an empirical model that assumes that the thickness of the adsorbed layer is one molecule (monolayer adsorption) in which adsorption process occurs at identical and equivalent definite localized sites (Pateiro-Moure et al., 2009; Kaur et al., 2016). Different investigations have reported on the increase in adsorption of herbicides in the presence of other adsorbing species, particularly those species that are also capable of forming complexes at the surface. This is likely the case of humic substances, such as humic acids (HAs) or fulvic acids (FAs), which have carboxylate groups in their structure, with the potential ability to affect the adsorption/desorption processes (Arroyave et al., 2016).

Cation exchange capacity (CEC) is also known to play a dominant role on the adsorption of cationic bipyridinium herbicides in natural soils, particularly in those with high natural organic matter and high mineral clay content (Pateiro-Moure et al., 2013). Herbicides in aqueous solutions might become positively charged through protonation adsorbing to humic and fulvic substances via cation exchange through carboxylic and phenolic groups contained in the structure. For the specific case of DQ and PQ are known to bind to more than one negatively charged site on soil humic colloids. In a similar way, cationic herbicide molecules are known to interact with the negatively charged sites of clay mineral particles contained in the soil matrix (Nir et al., 2006).

Some studies have encountered that under certain conditions the adsorption of herbicide on soils is at non-equilibrium process and physisorption and chemisorption are rather time dependent and intrasorbent diffusion might occur (Cáceres Jensen et al., 2019). Under those conditions, determining the adsorption kinetics will be more helpful to describe the rate of retention of the sorbate (i.e., herbicide) from an aqueous environment to the solid-phase interface at a given sorbent mass (i.e., soil sample or mineral clay), temperature, flow rate and $\mathrm{pH}$. The adsorption is then characterized by three stage process: (i) fast uptake on available sites; (ii) diffusion-immobilization in the soil sample, or clay mineral; and (iii) rapid uptake of the herbicide controlled by mass transfer mechanisms (Nir et al., 2006; Cáceres Jensen et al., 2019). PSO models have been used to describe the adsorption processes of non-ionizable herbicides on ultisols and andisols (Cáceres Jensen et al., 2019). Moreover, mineral clays with larger surface areas (e.g., Montmorillonite, Illite, and Cristobalite), might allow the herbicide molecules to reach the interior, making them a suitable adsorbent for the successful process of bipyridinium herbicides as observed in our experiments.

\section{CONCLUSIONS}

A numerous variety of agrochemicals are being introduced on the market each year, leading to soil and water pollution where applied and the potential risks with these compounds are still not properly understood (Pateiro-Moure et al., 2013). While poor adsorption of toxic agrochemicals on the soil will contribute to leaching into aquifers and direct surface water contamination (Teutli-Sequeira et al., 2020); high binding affinity for components of the soil matrix might indirectly contribute to groundwater pollution. Naturally occurring colloids (i.e., NOM and clay materials) with adsorbed toxic substances are known to remobilize by perturbations on the water chemistry (e.g., $\mathrm{pH}$, ionic strength) or changes in the aquifer hydraulics (e.g., rainfall or fractures) polluting the aquifer (Ryan and Elimelech, 1996).

This research study extends our knowledge on how DQ and $\mathrm{PQ}$, two toxic bipyridinium herbicides highly stable and soluble in water, adsorb onto the different components of the natural soil matrix (i.e., quartz sand, quartz sand coated with NOM, mineral clays, and natural topsoil). In experiments conducted on clean quartz sand (the most abundant component of the natural soil matrix), the adsorption was low $0.02-0.003$ $\mathrm{L} / \mathrm{mg}$ at both studied $\mathrm{pH}$ (i.e., 3.5 and 6.5 , respectively). Yet, for adsorption experiments conducted on precoated sand with $\mathrm{NOM}$, the adsorption seems to increase $1.3-6.3 \mathrm{~L} / \mathrm{mg}$ at $\mathrm{pH}$ 
6.5. This behavior is likely associated to the free carboxylates and phenolates contained in both model molecules (i.e., SRHA and SRFA) used in the study favoring the complexation with free ions present in the simulated granular medium. NOM (i.e., humic and fulvic acids) are an integral component of forest and agricultural fields.

Adsorption on isolated mineral clays were able to adsorb all the PQ and DQ, achieving up to $100 \%$ at $60 \mathrm{ppm}$ of each herbicide. Notably, experiments conducted on top natural soil reveal different adsorption behavior for each herbicide. Whereas, the PQ absorbed completely, the DQ presented an adsorption 1.3-0.9 L/mg. The inherent heterogeneity of natural granular materials found in subsurface environments remains another major challenge for the development of functional relationships between soil properties and agrochemical adsorption. Thus, further research is needed to extend this work to a wider range of environmentally relevant granular matrices and water chemistries.

\section{DATA AVAILABILITY STATEMENT}

The original contributions presented in the study are included in the article/Supplementary Materials, further inquiries can be directed to the corresponding author/s.

\section{REFERENCES}

Akhavein, A. A., and Linscott, D. L. (1968). "The dipyridylium herbicides, paraquat and diquat," in Residue Reviews/Rückstands-Berichte. Residue Reviews, Vol 23, ed F.A. Gunther (New York, NY: Springer).

Al-Ghouti, M. A., and Da'ana, D. (2020). Guidelines for the use and interpretation of adsorption isotherm models: a review. J. Hazard. Mater. 393:122383. doi: 10.1016/j.jhazmat.2020.122383

Amondham, W., Parkpian, P., Polprasert, C., DeLaune, R. D., and Jugsujinda, A. (2006). Paraquat adsorption, degradation, and remobilization in tropical soils of Thailand. J. Environ. Sci. Health B. 41, 485-507. doi: 10.1080/03601230600701635

Arroyave, J. M., Waiman, C. C., Zanini, G. P., and Avena, M. J. (2016). Effect of humic acid on the adsorption/desorption behavior of glyphosate on goethite. Isotherms Kinetics Chemosph. 145, 34-41. doi: 10.1016/j.chemosphere.2015.11.082

Aydin, S., Kajjumba, G. W., Emik, S., Ongen, A., and Ozcan, H. K. (2018). Modelling of Adsorption Kinetic Processes-Errors, Theory and Application. Turkey: IntechOpen Limited.

Azizullah, A., Khattak, M. N., Richter, P., and Häder, D. P. (2011). Water pollution in Pakistan and its impact on public health-a review. Environ. Int. 37, 479-497. doi: 10.1016/j.envint.2010.10.007

Barcelo, D. (1993). "Environmental analysis," in Techniques, Applications and Quality Assurance Vol. 13, (Spain: Elsevier Science). Available online at: https:// www.lsevier.com/books/environmental-analysis/barcelo/978-0-444-89648-3

Brigante, M., Zanini, G., and Avena, M. (2007). On the dissolution kinetics of humic acid particles: effects of $\mathrm{pH}$, temperature and $\mathrm{Ca} 2+$ concentration. Colloids Surf. A Physicochem. Eng. Aspects 294, 64-70. doi: 10.1016/j.colsurfa.2006.07.045

Brigante, M., Zanini, G., and Avena, M. (2010). Effect of humic acids on the adsorption of paraquat by goethite. J. Hazard. Mater. 184, 241-247. doi: 10.1016/j.jhazmat.2010.08.028

Brigante, M., Zanini, G., and Avena, M. (2013). Effects of montmorillonite on the chemical degradation kinetics of metsulfuron methyl in aqueous media. Appl. Clay Sci. 80-81, 211-218. doi: 10.1016/j.clay.2013.03.018

\section{AUTHOR CONTRIBUTIONS}

NT-J conducted the experiments and was involved in writing the manuscript with the help of RV-M and IQ as well as in data analysis, and method development. We acknowledge that all authors read and approved the final manuscript.

\section{ACKNOWLEDGMENTS}

We thank the DINV from Universidad Iberoamericana, Ciudad de México for supporting this research work (Fund \# F132020). Authors also thank Diego Nájera for providing support toward the drawing and schematics on the figures. Any results, findings, opinions, interpretation, conclusions or recommendations are those of authors and do not necessarily reflect the views of the funding supporting agencies.

\section{SUPPLEMENTARY MATERIAL}

The Supplementary Material for this article can be found online at: https://www.frontiersin.org/articles/10.3389/frwa. 2020.612742/full\#supplementary-material

Cáceres Jensen, L., Neira-Albornoz, A., and Escudey, M. (2019). Herbicides mechanisms involved in the sorption kinetic of ionisable and non ionisable herbicides: impact of physical/chemical properties of soils and experimental conditions. Kinetic Model. Enviromen. Syst. doi: 10.5772/intechopen.84906. [Epub ahead of print].

Chen, J. Y., Ko, C. H., Bhattacharjee, S., and Elimelech, M. (2001). Role of spatial distribution of porous medium surface charge heterogeneity in colloid transport. Colloids Surf. A Physicochem. Eng. Aspects 191, 3-15. doi: 10.1016/S0927-7757(01)00759-2

Cloarec, J. P., Chevalier, C., Genest, J., Beauvais, J., Chamas, H., Chevolot, Y., et al. (2016). $\mathrm{pH}$ driven addressing of silicon nanowires onto $\mathrm{Si}$ $3 \mathrm{~N} 4 / \mathrm{SiO} 2$ micro-patterned surfaces. Nanotechnology 27:295602. doi: 10.1088/0957-4484/27/29/295602

Díaz-Rodríguez, J., Lozano-Santa Cruz, R., Dávila-Alcocer, V. M., Vallejo, E., and Girón, P. (2011). Physical, chemical, and mineralogical properties of Mexico City sediments: a geotechnical perspective. Canad. Geotech. J. 35, 600-610. doi: 10.1139/t98-026

Evans, E. V. A., Mateo-Sagasta, J., Qadir, M., Boelee, E., and Ippolito, A. (2018). Agricultural water pollution: key knowledge gaps and research needs. Curr. Opin. Environ. Sustain. 36, 20-27. doi: 10.1016/j.cosust.2018. 10.003

Fortenberry, G. Z., Beckman, J., Schwartz, A., Prado, J. B., Graham, L. S., Higgins, S., et al. (2016). Magnitude and characteristics of acute paraquatand diquat-related illnesses in the US: 1998-2013. Environ. Res. 146, 191-199. doi: 10.1016/j.envres.2016.01.003

Gondar, D., López, R., Antelo, J., Fiol, S., and Arce, F. (2012). Adsorption of paraquat on soil organic matter: effect of exchangeable cations and dissolved organic carbon. J. Hazard. Mater. 235(Suppl. C), 218-223. doi: 10.1016/j.jhazmat.2012.07.044

Hallett, P. D., Bachmann, J., Czachor, H., Urbanek, E., and Zhang, B. (2011). "Hydrophobicity of soil," in Encyclopedia of Agrophysics, eds J. Gliński, J. Horabik and J. Lipiec (Dordrecht: Springer Netherlands), 378-384.

Iglesias, A., López, R., Gondar, D., Antelo, J., Fiol, S., and Arce, F. (2010). Adsorption of paraquat on goethite and humic acid-coated goethite. J. Hazard. Mater. 183, 644-668. doi: 10.1016/j.jhazmat.2010.07.077 
Jegatheesan, V., and Vigneswaran, S. (2005). Deep bed filtration: mathematical models and observations. Crit. Rev. Environ. Sci. Technol. 35, 515-569. doi: 10.1080/10643380500326432

Kaur, P., Kaur, P., Singh, K., and Kaur, M. (2016). Adsorption and desorption characteristics of pretilachlor in three soils of Punjab. Water Air Soil Pollut. 227:376. doi: 10.1007/s11270-016-3074-x

Khan, S. U., and Schnitzer, M. (1978). Chapter 4 the interaction of organic matter with pesticides. Dev. Soil Sci. 8, 137-171. doi: 10.1016/S0166-2481(08)70019-9

Litton, G. M., and Olson, T. M. (1996). Particle size effects on colloid deposition kinetics: evidence of secondary minimum deposition. Colloids Surf. A Physicochem. Eng. Aspects 107, 273-283. doi: 10.1016/0927-7757(95)03343-2

Nethaji, S., Sivasamy, A., and Mandal, A. B. (2013). Adsorption isotherms, kinetics and mechanism for the adsorption of cationic and anionic dyes onto carbonaceous particles prepared from Juglans regia shell biomass. Int. J. Environ. Sci. Tech. 10, 231-242. doi: 10.1007/s13762-012-0112-0

Nir, S., El-Nahhal, Y., Undabeytia, T., Rytwo, G., Polubesova, T., Mishael, Y., et al. (2006). Chapter 11.2 clays and pesticides. Dev. Clay Sci. 1, 677-691. doi: 10.1016/S1572-4352(05)01021-4

Pateiro-Moure, M., Arias-Estévez, M., and Simal-Gándara, J. (2010). Competitive and non-competitive adsorption/desorption of paraquat, diquat and difenzoquat in vineyard-devoted soils. J. Hazard. Mater. 178, 194-201. doi: 10.1016/j.jhazmat.2010.01.063

Pateiro-Moure, M., Arias-Estévez, M., and Simal-Gándara, J. (2013). A critical review on the environmental fate of quaternary ammonium herbicides in soils devoted to Vineyards. Environ. Sci. Technol. 47, 4984-4998. doi: $10.1021 /$ es400755h

Pateiro-Moure, M., Pérez-Novo, C., Arias-Estévez, M., Rial-Otero, R., and SimalGándara, J. (2009). Effect of organic matter and iron oxides on quaternary herbicide sorption-desorption in vineyard-devoted soils. J. Colloid Interface Sci. 333, 431-438. doi: 10.1016/j.jcis.2009.02.019

Rasheed, T., Bilal, M., Nabeel, F., Adeel, M., and Iqbal, H. M. N. (2018). Environmentally-related contaminants of high concern: potential sources and analytical modalities for detection, quantification, and treatment. Environ. Int. 122, 56-66. doi: 10.1016/j.envint.2018.11.038

Ryan, J. N., and Elimelech, M. (1996). Colloid mobilization and transport in groundwater. Colloids Surf. A. 107, 1-56. doi: 10.1016/0927-7757(95)03384-x

Rytwo, G., Nir, S., Crespin, M., and Margulies, L. (1996). Adsorption and interactions of diquat and paraquat with montmorillonite. Soil Sci. Soc. Am. J. 60, 601-610. doi: 10.2136/sssaj1996.03615995006000020038x
Sechi, G. P., Agnetti, V., Piredda, M., Canu, M., Deserra, F., Omar, H. A., et al. (1992). Acute and persistent parkinsonism after use of diquat. Neurology 42, 261-263. doi: 10.1212/WNL.42.1.261

Teutli-Sequeira, A., Vasquez-Medrano, R., Prato-Garcia, D., and Ibanez, J. G. (2020). Solar photo-assisted degradation of bipyridinium herbicides at circumneutral $\mathrm{pH}$ : a life cycle assessment approach. Processes. 8:1117. doi: $10.3390 /$ pr8091117

Thomaz, E. L., Antoneli, V., and Doerr, S. H. (2014). Effects of fire on the physicochemical properties of soil in a slash-andburn agriculture. Catena 122, 209-215. doi: 10.1016/j.catena.2014. 06.016

Valin, H., Sands, R. D., van der Mensbrugghe, D., Nelson, G. C., Ahammad, H., Blanc, E., et al. (2014). The future of food demand: understanding differences in global economic models. Agric. Econ. 45, 51-67. doi: 10.1111/agec.12089

Watts, R. J. (1998). Hazardous Wastes: Sources, Pathways, Receptors. New York, NY: John Wiley and Sons, Inc.

World Health Organization. Promotion of Chemical Safety, Unit, and Safety International Programme on Chemical (1992). The WHO Recommended Classification of pesticides by Hazard and Guidelines to Classification 199293. Geneva: Forty Fifth World Health Organization. Available online at: https://apps.who.int/iris/bitstream/handle/10665/175580/WHA45_16_eng. pdf? sequence $=1$ \&isAllowed $=y$

Yeates, G. W., Stout, J. D., Ross, D. J., Dutch, M. E., and Thomas, R. F. (1976). Long-term effects of paraquat-diquat and additional weed control treatments on some physical, biological and respiratory properties of a soil previously under grass. N. Z. J. Agric. Res. 19, 51-61. doi: 10.1080/00288233.1976.104 21046

Conflict of Interest: The authors declare that the research was conducted in the absence of any commercial or financial relationships that could be construed as a potential conflict of interest.

Copyright (c) 2021 Tadeo-Jalife, Vasquez-Medrano and Quevedo. This is an openaccess article distributed under the terms of the Creative Commons Attribution License (CC BY). The use, distribution or reproduction in other forums is permitted, provided the original author(s) and the copyright owner(s) are credited and that the original publication in this journal is cited, in accordance with accepted academic practice. No use, distribution or reproduction is permitted which does not comply with these terms. 